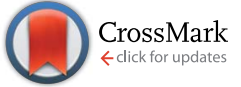

Cite this: Chem. Sci., 2015, 6, 6739

\title{
The divergent effects of strong NHC donation in catalysis $\uparrow$
}

\author{
Justin A. M. Lummiss, ${ }^{a}$ Carolyn S. Higman, ${ }^{a}$ Devon L. Fyson, ${ }^{a}$ Robert McDonald ${ }^{\text {b }}$ \\ and Deryn E. Fogg ${ }^{\star a}$
}

Strong $\sigma$-donation from $\mathrm{NHC}$ ligands ( $\mathrm{NHC}=\mathrm{N}$-heterocyclic carbene) is shown to have profoundly conflicting consequences for the reactivity of transition-metal catalysts. Such donation is regarded as central to high catalyst activity in many contexts, of which the second-generation Grubbs metathesis catalysts $\left(\mathrm{RuCl}_{2}(\mathrm{NHC})\left(\mathrm{PCy}_{3}\right)(=\mathrm{CHPh}), \mathrm{Gll}\right)$ offer an early, prominent example. Less widely recognized is the dramatically inhibiting impact of $\mathrm{NHC}$ ligation on initiation of $\mathrm{Gll}$, and on re-entry into the catalytic cycle from the resting-state methylidene species $\mathrm{RuCl}_{2}(\mathrm{NHC})(\mathrm{PCy})\left(=\mathrm{CH}_{2}\right), \mathrm{Gllm}$. Both Gll and the methylidene complexes are activated by dissociation of $\mathrm{PCy}_{3}$. The impact of $\mathrm{NHC}$ donicity on the rate of $\mathrm{PCy}_{3}$ loss is explored in a comparison of $s-$ Gllm, vs. $u$-Gllm, in which the $\mathrm{NHC}$ ligand is saturated $\mathrm{H}_{2} \mathrm{IMes}$ or unsaturated IMes, respectively. PCy $\mathrm{P}_{3}$ loss is nearly an order of magnitude slower for the IMes derivative (a difference that is replicated, albeit smaller, for the benzylidene precatalysts GII). Proposed as an overlooked contributor to these rate differences is an increase in the Ru-PCy $y_{3}$ bond strength arising from $\pi$-back-donation onto the phosphine ligand. Strong $\sigma$-donation from the IMes ligand, coupled with the inability of this unsaturated $\mathrm{NHC}$ to participate in significant $\pi$-backbonding, amplifies $\mathrm{Ru} \rightarrow$ $\mathrm{PCy}_{3} \pi$-back-donation. The resulting increase in $\mathrm{Ru}-\mathrm{P}$ bond strength greatly inhibits entry into the active cycle. For $s$-Gll, in contrast, the greater $\pi$-acceptor capacity of the NHC ligand enables competing Ru $\rightarrow \mathrm{H}_{2}$ IMes back-donation (as confirmed by NOE experiments, which reveal restricted rotation about the $\mathrm{Ru}-\mathrm{NHC}$ bond for $\mathrm{H}_{2} I$ Mes, but not IMes). $\mathrm{Ru} \rightarrow \mathrm{PCy}_{3}$ back-donation is thus attenuated in the $\mathrm{H}_{2} I$ Mes complexes, accounting for the greater lability of the $\mathrm{PCy}_{3}$ ligand in s-Gllm and s-Gll. Similarly inhibited initiation is predicted for other metal-NHC catalysts in which a $\pi$-acceptor ligand $L$ must be dissociated to permit substrate binding. Conversely, enhanced reactivity can be expected where such $L$ ligands are pure $\sigma$-donors. These effects are expected to be particularly dramatic where the NHC ligand has minimal $\pi$-acceptor capacity (as in the unsaturated Arduengo carbenes), and in geometries that maximize $\mathrm{NHC}-\mathrm{M}-\mathrm{L}$ orbital interactions.

Accepted 5th October 2015

DOI: $10.1039 / \mathrm{c} 5 \mathrm{sc} 02592 \mathrm{c}$

www.rsc.org/chemicalscience
NHC donation to influence bonding interactions with other ligands present, both ancillary ligands and bound substrate. ${ }^{\mathbf{9 - 1 1}}$

In a leading recent example, the Neidig group reported evidence for ground-state weakening of the $\mathrm{Fe}-\mathrm{Cl}$ bond by $\sigma$ donation from the NHC ligand in tetrahedral $\mathrm{FeX}_{2}(\mathrm{NHC})_{2}$ complexes. ${ }^{9}$ The implied potential labilization of $\pi$-donor ligands by NHC ligands is of keen interest. The potentially broad implications of such behaviour in catalysis prompted us to explore the impact of NHC donicity on neutral, dative donor ligands, particularly in geometries that reinforce inter-ligand electronic communication. Here we demonstrate the impact of the NHC ligand on trans-ligand binding, in an important example drawn from olefin metathesis.

The breakthrough activity of the second-generation Grubbs catalysts, ${ }^{12,13}$ which greatly expanded the scope of the reaction relative to the parent system GI (Fig. 1), was originally attributed to labilization of the $\sigma$-donor $\mathrm{PCy}_{3}$ ligand by the strongly donating trans-NHC ligand. ${ }^{\mathbf{1 4}}$ In a seminal kinetics study,
${ }^{a}$ Center for Catalysis Research \& Innovation and Department of Chemistry, University of Ottawa, Ottawa, K1N 6N5, Canada.E-mail: dfogg@uottawa.ca

${ }^{b}$ Department of Chemistry, University of Alberta, Edmonton, T6G 2G2, AB, Canada

$\uparrow$ Electronic supplementary information (ESI) available: Rate profiles for decomposition of $\boldsymbol{u}$-GIIm and $\boldsymbol{s}$-GIIm; X-ray crystallographic details; NOESY spectra, and derivation of the $\left[\mathrm{PCy}_{3}\right]$-independence of decomposition. CCDC 1400077. For ESI and crystallographic data in CIF or other electronic format see DOI: $10.1039 / \mathrm{c} 5 \mathrm{sc} 02592 \mathrm{c}$ 


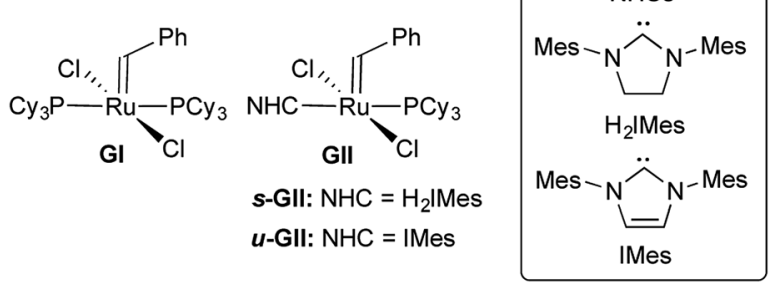

Fig. 1 The first and second-generation Grubbs catalysts, Gl and GII.

however, Grubbs and co-workers demonstrated that $\mathrm{PCy}_{3}$ loss is in fact slower for GII than the first-generation catalyst GI. ${ }^{\mathbf{1 4}}$

A leading explanation for this "inverse trans effect" highlights alkylidene rotation as a trigger for $\mathrm{PCy}_{3}$ dissociation, pointing out higher torsional barriers to such rotation in the NHC complexes. ${ }^{15}$ An alternative view emerges from Kennepohl's discovery, based on groundbreaking X-ray absorbance spectroscopy (XAS) studies, that the Ru center in $s$-GII is more electropositive than that in GI. ${ }^{16}$ This implies that the NHC ligand is a poor net charge donor, relative to $\mathrm{PCy}_{3}$. An increased electrostatic attraction between the more electron-deficient $\mathrm{Ru}$ center in GII and the strongly-donating $\mathrm{PCy}_{3}$ ligand was proposed to account for the reduced phosphine lability.

Adopting the majority view of NHC ligands as strong $\sigma$ donors, we speculated that NHC donation might itself be a factor: that strong $\sigma$-donation could in fact strengthen the trans $\mathrm{Ru}-\mathrm{PCy}_{3}$ bond, by increasing $\mathrm{Ru} \rightarrow \mathrm{PCy}_{3}$ backbonding. In exploring this possibility, we focused on the methylidene species GIIm (Fig. 2), to eliminate steric or $\pi$-stacking effects associated with the benzylidene moiety, and electronic perturbation arising from benzylidene $\pi$-acidity. GIIm is, moreover, a key player in catalysis, as the resting-state species in most ring-closing and cross-metathesis reactions promoted by GII. That is, because GIIm is thermodynamically stable relative to both the benzylidene precatalyst GII, and other ruthenium species present in the catalytic cycle, its concentration builds up during metathesis. Recently-developed ${ }^{17}$ routes to the secondgeneration methylidene complexes enable their direct study.

The availability of the closely related complexes $\boldsymbol{u}$-GIIm and $s$-GIIm permits the effect of NHC donicity on trans- $\mathrm{PCy}_{3}$ bonding to be assessed with minimal extraneous perturbation. ${ }^{18,19}$ The $\pi$-acceptor capacity of saturated NHCs such as $\mathrm{H}_{2} \mathrm{IMes}$, first proposed more than a decade ago, has seen much discussion. ${ }^{10,11,16,19-29}$ In recent years, the focus has shifted to means of deconvoluting NHC $\sigma$-donor and $\pi$-acceptor properties. ${ }^{23-26}$ While unsaturated Arduengo NHCs are generally viewed as poor $\pi$-acceptors, accumulating evidence suggests that their saturated analogues can exhibit significant $\pi$ acidity. ${ }^{10,11,16,19-28}$ If $\sigma$-donation from the $\mathrm{H}_{2} \mathrm{IMes}$ ligand in $s$ -
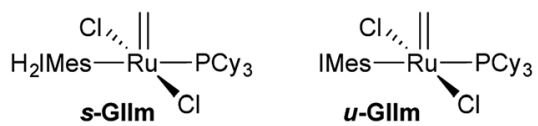

Fig. 2 The off-cycle resting states for GII: methylidene complexes sGllm and $u$-GIIm.
GIIm is countered by Ru-NHC backbonding, we considered that this should result in experimentally observable distinctions between the $\mathrm{H}_{2} \mathrm{IMes}$ and IMes complexes, which could potentially be correlated with differences in $\mathrm{PCy}_{3}$ lability.

Here we quantify the differences in $\mathrm{PCy}_{3}$ lability in GIIm; we demonstrate that strong $\sigma$-donation from the $\mathrm{H}_{2} \mathrm{IMes}$ ligand is indeed tempered by $\pi$-backbonding onto the NHC, as evidenced by restricted rotation about the $\mathrm{Ru}-\mathrm{H}_{2} \mathrm{IMes}$ bond, and that $\mathrm{PCy}_{3}$ loss is dramatically slower for the IMes system, in which NHC $\sigma$-donation is unrelieved by NHC $\pi$-acidity (as confirmed by room-temperature rotation about the Ru-IMes bond). Based on these observations, we propose that enhanced backbonding onto the $\mathrm{PCy}_{3}$ ligand is a key, overlooked contributor to the low phosphine lability characteristic of the second-generation Grubbs catalysts. Such $\mathrm{Ru} \rightarrow \mathrm{PCy}_{3}$ backbonding relieves the heightened electron density at $\mathrm{Ru}$ that would otherwise result from strong NHC $\sigma$-donation, and consequently strengthens the Ru-P bond. The broader implications for catalysis are discussed.

\section{Results and discussion}

\section{Assaying $\mathrm{PCy}_{3}$ lability for GIIm}

Direct assessment of $\mathrm{PCy}_{3}$ lability for the second-generation methylidene complexes is hampered by a combination of strong phosphine binding and thermal instability. Even for the more labile benzylidene pre-catalysts, $\mathrm{PCy}_{3}$ loss from the IMes derivative $\boldsymbol{u}$-GII was 640 times slower than from the first-generation complex GI. ${ }^{14}$ Qualitative evidence indicated drastically lower lability for the methylidene complexes GIIm, but attempts to measure rate constants were thwarted by decomposition at the temperatures required to induce $\mathrm{PCy}_{3}$ exchange $\left(c a .85^{\circ} \mathrm{C}\right) .^{14}$

This underscores the point that the thermodynamic stability of GIIm relative to other catalytically relevant species does not equate to stability against decomposition. Indeed, the methylidene complexes are significantly more vulnerable than their benzylidene precursors, owing to their susceptibility to nucleophilic attack at the $\mathrm{Ru}=\mathrm{CH}_{2}$ site. ${ }^{30-32}$

We considered that this vulnerability, which constituted a problem in the original exchange experiments, could offer a disguised opportunity to assess phosphine lability. Specifically, if decomposition of GIIm proceeds via rate-limiting loss of $\mathrm{PCy}_{3},{ }^{30}$ then the rate of decomposition reports on the rate of $\mathrm{PCy}_{3}$ loss. To confirm that this reaction proceeds only via fourcoordinate Ru-1, we examined the impact of added $\mathrm{PCy}_{3}$ on the reaction kinetics. If phosphine attack occurs on Ru-1 (Scheme 1a), the rate of decomposition should be unaffected, for the reasons discussed below. If, however, GIIm can react directly with $\mathrm{PCy}_{3}$ (Scheme 1b), decomposition should be accelerated.

As seen from Fig. 3, the rate of decomposition is unaffected by added $\mathrm{PCy}_{3}$, indicating reaction via the dissociative pathway (Scheme 1a). The preference is unsurprising, given steric restrictions on the approach of $\mathrm{PCy}_{3}$ to the methylidene carbon in five-coordinate GIIm. The absence of an inverse dependence on $\left[\mathrm{PCy}_{3}\right]$ may at first seem inconsistent with rate-determining loss of $\mathrm{PCy}_{3}$. This reflects the participation of $\mathrm{PCy}_{3}$ in the $k_{2}$ step (i.e. the Ru-1 $\rightarrow$ Ru-2 transformation), as well as the $k_{-1}$ step 
(a) Dissociative: rate of decomposition is independent of $\left[\mathrm{PCy}_{3}\right]$

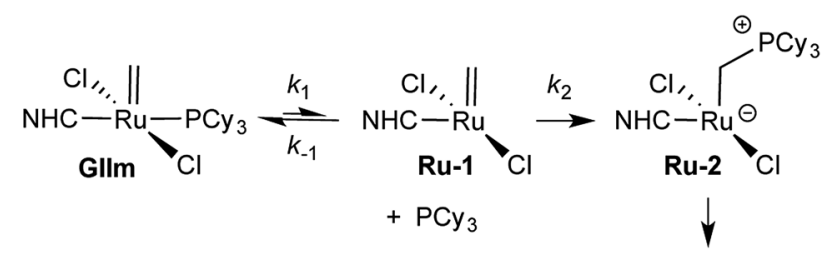

(b) Associative: rate of decomposition is accelerated by added $\mathrm{PCy}_{3}$

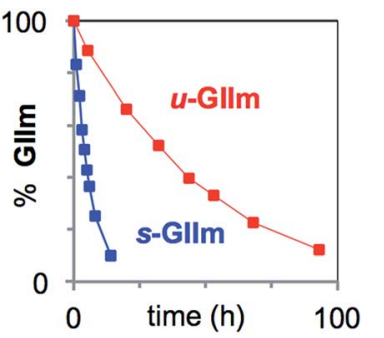

Fig. 4 Assessing rates of $\mathrm{PCy}_{3}$ loss from the decomposition of $s-\mathrm{Gllm}$ and $u$-Gllm in $C_{6} D_{6}$. Left: Rate curves at $60{ }^{\circ} \mathrm{C}$. Right: Initial rate constants and $k_{\text {rel }}$ (normalized to $u$-Gllm) at $40{ }^{\circ} \mathrm{C}, 60^{\circ} \mathrm{C}$, and $80^{\circ} \mathrm{C}$. For half-lives and rate plots at other temperatures, see the ESI. $\dagger$

trend for the parent benzylidene catalysts, with $k_{1}$ for $\boldsymbol{u}$-GII being seven-fold lower than for $\boldsymbol{s}$-GII. ${ }^{34}$

The lower phosphine lability of $\boldsymbol{u}$-GIIm relative to $\boldsymbol{s}$-GIIm was maintained in other solvents (Fig. 5). In these experiments, the proportion of GIIm remaining after $6 \mathrm{~h}$ at $60^{\circ} \mathrm{C}$ was measured. Decomposition was marginally faster in chlorinated media than in aromatic solvents, and dramatically faster in the coordinating solvent THF. The solvent-dependence of $\mathrm{PCy}_{3}$ dissociation thus follows the trend $\mathrm{C}_{7} \mathrm{H}_{8} \sim \mathrm{C}_{6} \mathrm{H}_{6}<\mathrm{CH}_{2} \mathrm{Cl}_{2} \sim \mathrm{CHCl}_{3} \ll$ THF, for both the IMes and $\mathrm{H}_{2}$ IMes methylidene complexes. This agrees with the trend previously established for initiation of the benzylidene precatalyst $s$-GII, for which the rate-determining step is likewise $\mathrm{PCy}_{3}$ loss. ${ }^{14}$

The consistency in these reactivity patterns, as well as the excellent agreement with the relative rate constants computed by Jensen (see above), validate the use of decomposition rates to quantify rates of $\mathrm{PCy}_{3}$ loss from GIIm. Also noteworthy is the close correlation between relative rates of initiation of GII in different solvents, and relative rates of decomposition of GIIm. This correlation accounts for the observation that increasing the rate of initiation does not improve reaction rates for the Grubbs catalysts. ${ }^{35}$ Instead, because productive metathesis generates an unprotected methylidene moiety, faster initiation is offset by faster methylidene abstraction by free $\mathrm{PCy}_{3}$.

\section{Crystallographic analysis: comparison of $u$-GIIm with $s$-GIIm}

In the hope of gaining insight into the bonding interactions that distinguish the IMes and $\mathrm{H}_{2}$ IMes analogues, we undertook

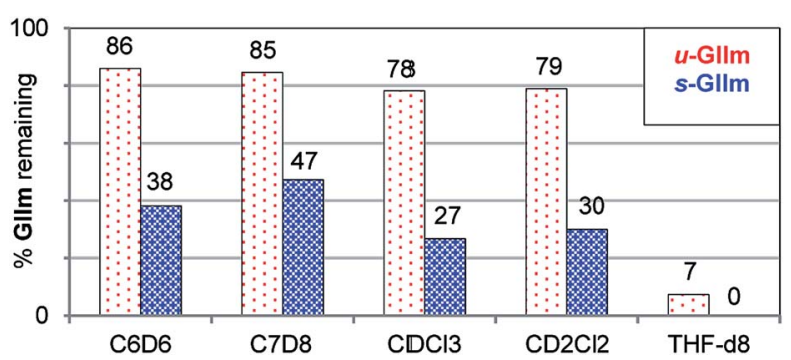

Fig. 5 Assessing the relative stability of $u$-GIIm and s-Gllm in common solvents, as a proxy for $\mathrm{PCy}_{3}$ lability $\left(6 \mathrm{~h}, 60{ }^{\circ} \mathrm{C}\right.$ oil-bath; ${ }^{1} \mathrm{H}$ NMR integration vs. TMB). Key chemical shift data for Gll and Gllm in these solvents are tabulated in the ESI. $\uparrow$ 


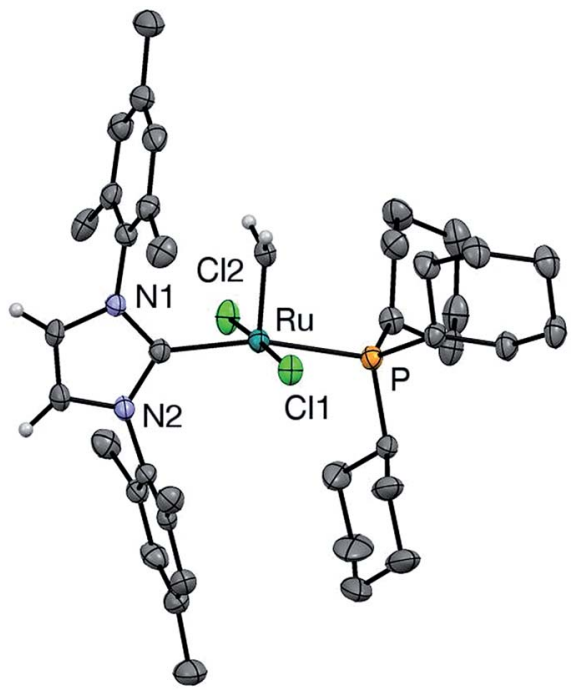

Fig. 6 Perspective view of $u$-Gllm. Non-hydrogen atoms are represented by Gaussian ellipsoids at the $30 \%$ probability level. Hydrogen atoms on methylidene and NHC backbone carbons are shown with arbitrarily small thermal parameters; other hydrogens are not shown.

Table 1 Key bond lengths and angles for Gllm complexes

\begin{tabular}{lll}
\hline & $\boldsymbol{u}$-GIIm & $\boldsymbol{s}$-GIIm ${ }^{36}$ \\
\hline $\boldsymbol{\tau}$-parameter & 0.19 & 0.19 \\
& & \\
Bond lengths $(\AA)$ & & \\
$\mathrm{Ru}-\mathrm{P}$ & $2.4174(16)$ & $2.427(1)$ \\
$\mathrm{Ru}=\mathrm{C}$ & $1.797(7)$ & $1.800(2)$ \\
$\mathrm{Ru}-\mathrm{C}_{\mathrm{NHC}}$ & $2.077(5)$ & $2.065(2)$ \\
$\mathrm{Ru}-\mathrm{Cl}(1)$ & $2.389(2)$ & $2.393(1)$ \\
$\mathrm{Ru}-\mathrm{Cl}(2)$ & $2.381(2)$ & $2.379(1)$ \\
& & \\
$\mathrm{Bond}$ angles $\left({ }^{\circ}\right)$ & & $177.05(2)$ \\
$\mathrm{Cl}-\mathrm{Ru}-\mathrm{Cl}$ & $176.99(6)$ & $165.81(5)$ \\
$\mathrm{P}-\mathrm{Ru}-\mathrm{C}_{\mathrm{NHC}}$ & $165.63(16)$ & $96.90(7)$ \\
$\mathrm{P}-\mathrm{Ru}=\mathrm{C}$ & $97.2(2)$ & $92.89(7)$ \\
$\mathrm{Cl}(1)-\mathrm{Ru}=\mathrm{C}$ & $93.1(2)$ & $89.77(7)$ \\
$\mathrm{Cl}(2)-\mathrm{Ru}=\mathrm{C}$ & $89.9(2)$ & $97.29(8)$ \\
$\mathrm{C}_{\mathrm{NHC}}-\mathrm{Ru}=\mathrm{C}$ & $97.2(3)$ & \\
& &
\end{tabular}

a crystallographic study of $\boldsymbol{u}$-GIIm, for comparison with the reported structure of $\boldsymbol{s}$-GIIm. ${ }^{36}$ The instability of these complexes in solution can be minimized by low-temperature handling, and X-ray quality crystals of $\boldsymbol{u}$-GIIm deposited from concentrated solutions in toluene over days at $-35{ }^{\circ} \mathrm{C}$. The ORTEP plot is shown in Fig. 6; key bond lengths and angles are compared with those for $\boldsymbol{s}$-GIIm in Table 1.

The geometry at $\mathrm{Ru}$ is square pyramidal in both cases, as indicated by the $\tau$ values of 0.19 ( $c f . \tau=0$ for a perfect square pyramid, and $\tau=1$ for a perfect trigonal bipyramid). ${ }^{37}$ While the $\mathrm{P}-\mathrm{Ru}-\mathrm{C}_{\mathrm{NHC}}$ angle shows some distortion from the $180^{\circ}$ ideal (ca. $166^{\circ}$ in both $\boldsymbol{u}$-GIIm and $\boldsymbol{s}$-GIIm), excellent orbital communication is expected between the trans-disposed phosphine and NHC ligands. Importantly, however, the Ru-P bond distances in $\boldsymbol{s}$-GIIm and $\boldsymbol{u}$-GIIm are statistically indistinguishable, despite the nearly tenfold difference in phosphine lability. The absence of a correlation between $\mathrm{Ru}-$ $\mathrm{PCy}_{3}$ bond length and bond strength was pointed out for the parent benzylidene complexes, ${ }^{\mathbf{1 4}}$ but has gone widely unnoticed. Frenking has pointed out that metal-ligand bond lengths are not reliable indicators of bond strength, where the ligand can function as an acceptor as well as a donor. ${ }^{38}$ The $\pi$-acceptor properties of the phosphine ligand in the NHC complexes are discussed below.

\section{Molecular dynamics study: $\mathbf{R u}=\mathrm{C}_{\mathrm{NHC}}$ rotation and bond order}

More direct insight emerged from a molecular dynamics study, in which 2D NOESY-NMR was used to assess rotational exchange between the mesityl rings above and below the basal plane (Fig. 7, top). Exchange cross-peaks were observed for all four unique mesityl methyl signals in $\boldsymbol{u}$-GIIm and $\boldsymbol{u}$-GII, indicating rotation about the $\mathrm{Ru}$-IMes bond at room temperature (Fig. 7a). No such cross-peaks were evident for $\boldsymbol{s}$-GIIm and $\boldsymbol{s}$-GII (Fig. 7b), even for the well-resolved $p$-Me singlets (the $o$-Me singlets are less well resolved, perhaps due to $[\mathrm{Ru}]=\mathrm{CHPh}$ swiveling). Slower rotation of the $\mathrm{H}_{2}$ IMes ligand in both the methylidene complex $\boldsymbol{s}$-GIIm and its benzylidene parent $\boldsymbol{s}$-GII is important in indicating that restricted rotation is unrelated to the steric demand of the $[\mathrm{Ru}]=\mathrm{CHR}$ substituent.

Restricted rotation about the $\mathrm{Ru}-\mathrm{H}_{2}$ IMes bond implies increased $\mathrm{Ru}-\mathrm{C}_{\mathrm{NHC}}$ double-bond character, arising from $\pi$ back-donation from the metal onto the vacant $p$-orbital on the NHC carbon. Free rotation of the IMes ligand, in contrast, indicates a high proportion of single-bond character in the $\mathrm{Ru}-$ $\mathrm{C}_{\mathrm{NHC}}$ bond. This accords with the experimental and computational findings described above, showing stronger $\pi$-acceptor character for the $\mathrm{H}_{2}$ IMes ligand than IMes. Bertrand and coworkers drew a similar conclusion in a comparative study of $\mathrm{H}_{2} \mathrm{IPr}-\mathrm{PPh}$ and IPr-PPh adducts, also on the basis of a solution dynamics study (IPr = 1,3-bis(2,6-diisopropylphenyl)imidazol-2ylidene). ${ }^{23}$ Thus, the saturated $\mathrm{H}_{2}$ IPr derivative was classified as a phosphaalkene species, and the unsaturated IPr adduct as a phosphinidene.

\section{Origin of the inverse trans effect}

As noted in the Introduction, the origin of the dramatically reduced phosphine lability in the second-generation Grubbs catalysts is a puzzle of long standing. Straub suggested that faster $\mathrm{PCy}_{3}$ loss from $\mathbf{G I}$ is due to repulsive interactions between the chloride ligands and the $\beta$-hydrogen atoms of the cyclohexyl rings. ${ }^{39}$ More recently, Yang, Truhlar and co-workers reported DFT evidence showing that alkylidene rotation functions as a toggle to trigger $\mathrm{PCy}_{3}$ dissociation, and that the torsional barriers to rotation are higher for $s$-GII. ${ }^{15}$

Kennepohl's XAS study stands out, however, for the unexpected revelation that $s$-GII exhibits a higher 1 s ionization potential for $\mathrm{Ru}$ - that is, a more electron-deficient metal center - than does the first-generation parent GI. We suggest that this is due to enhanced $\pi$-donation from $\mathrm{Ru}$ onto the $\mathrm{NHC}$ and $\mathrm{PCy}_{3}$ ligands. It should be noted that the Kennepohl study examined 

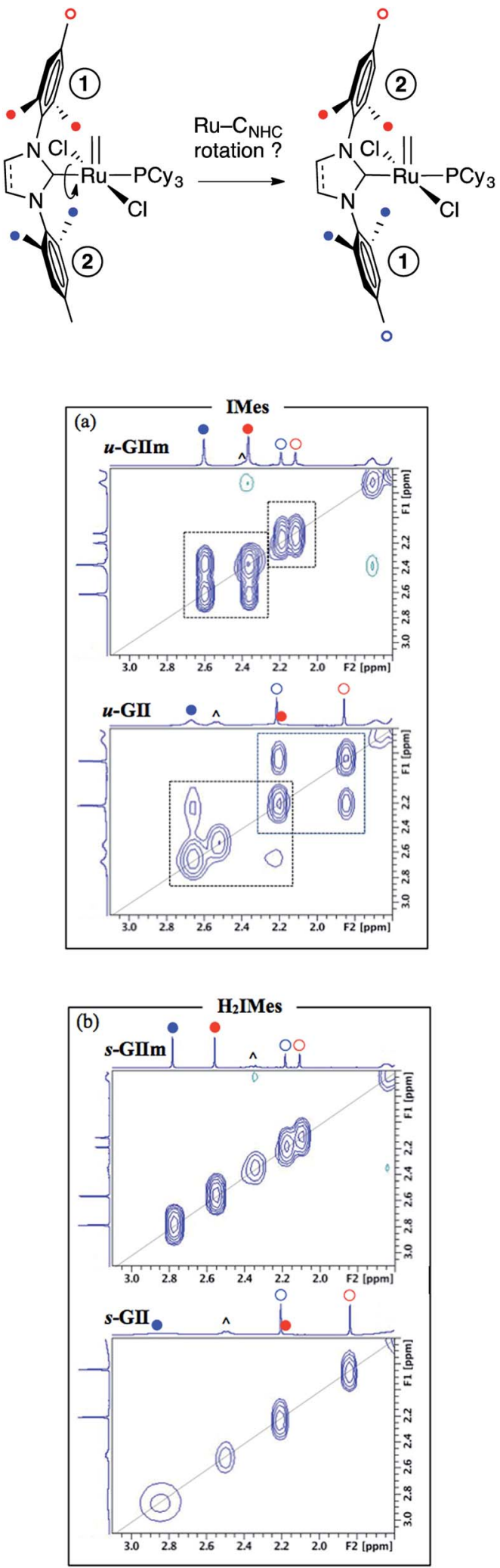

Fig. $7{ }^{1} \mathrm{H}-{ }^{1} \mathrm{H}$ NOESY spectra showing dependence of $\mathrm{Ru}-\mathrm{NHC}$ rotation on $\mathrm{NHC}$ unsaturation. (a) Exchange correlations between mesityl methyl signals for the IMes derivatives. (b) Absence of correlations for the $\mathrm{H}_{2} \mathrm{IMes}$ analogues. (all in $\mathrm{C}_{6} \mathrm{D}_{6}, 500.1 \mathrm{MHz}, 25^{\circ} \mathrm{C}, 1.5 \mathrm{~s}$ relaxation delay). Symbols: $(\wedge)=\mathrm{Cy}$; for others, see top. this possibility for $\boldsymbol{s}$-GIIm. It was rejected, as calculations at the level of theory then available indicated limited $\mathrm{Ru} \rightarrow \mathrm{PCy}_{3}$ backbonding (in consequence of which, stronger $\mathrm{PCy}_{3}$ binding was attributed to an enhanced $\mathrm{Ru} / \mathrm{PCy}_{3}$ electrostatic attraction). Importantly, however, consideration of dispersion forces has since emerged as critical to quantitative evaluation of the $\mathrm{PCy}_{3}$ dissociation step. ${ }^{40}$

The limited role heretofor assigned to $\mathrm{Ru}-\mathrm{PCy}_{3} \pi$-acceptor interactions in this system is perhaps unsurprising, given the widespread perception of alkylphosphines as strong $\sigma$-donors and weak $\pi$-acceptors (a situation also encountered in the context of NHC donicity; see above). Here too, however, a reevaluation is in progress. In an analysis of electron density and structural effects, Leyssens, Harvey and co-workers demonstrated that $\pi$-backbonding from the metal atom onto the $\mathrm{P}-\mathrm{R} \sigma^{*}$-antibonding orbitals can represent a significant component of metal-phosphine bonding, including for trialkylphosphine complexes. ${ }^{41}$ A recent leading review of computational approaches to the understanding of metalphosphorus bonding likewise emphasizes that calculated ligand descriptors for phosphine ligands must consider their $\pi$-acceptor character. ${ }^{42}$

In light of these developments, we suggest that $\pi$-backdonation onto the phosphine is a significant, overlooked contribution to the low $\mathrm{PCy}_{3}$ lability in the second-generation Grubbs catalysts. The potent $\sigma$-donor properties of the NHC ligand constrain back-donation onto any $\pi$-acceptor ligands present. For precatalyst $\boldsymbol{s}$-GII, three ligands can participate in $\pi$ backbonding: $\mathrm{H}_{2} \mathrm{IMes}, \mathrm{PCy}_{3}$, and benzylidene. ${ }^{39}$ In the case of $\boldsymbol{u}$ GIIm, the poor $\pi$-acceptor character of the IMes and methylidene ligands leaves the $\mathrm{PCy}_{3}$ ligand as the sole entity that can ameliorate the buildup of charge on the metal. We propose that this buildup is offset for $\boldsymbol{u}$-GIIm by greater $\mathrm{Ru} \rightarrow \mathrm{PCy}_{3}$ backdonation (Fig. 8), and for $s$-GIIm, by greater $\mathrm{Ru} \rightarrow \mathrm{H}_{2} \mathrm{IMes}$ backdonation, accompanied by a lesser amount of $\mathrm{Ru} \rightarrow \mathrm{PCy}_{3}$ backdonation. This would account for the poor net charge donation from the saturated NHC ligand observed in the Kennepohl study. Also relevant in this context is an energy decomposition analysis by Poblet and co-workers, which suggested that the $\pi$ acceptor capacity of $\mathrm{H}_{2}$ IMes reduces total charge donation to the metal for $s$-GIIm, relative to its IMes analogue. ${ }^{21}$

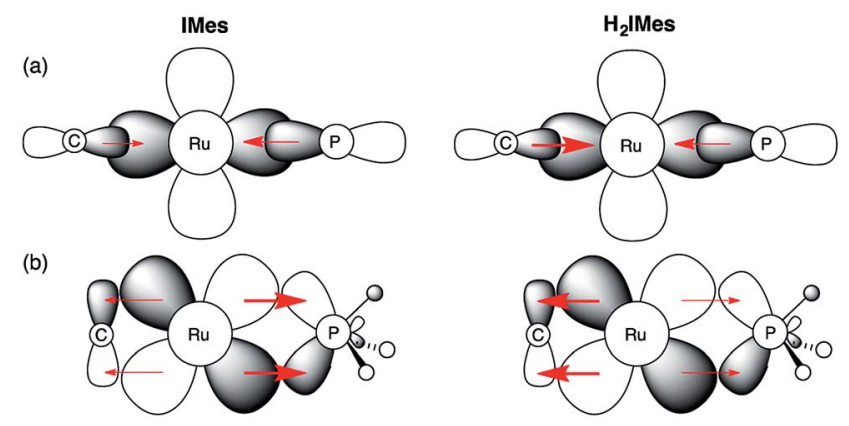

Fig. 8 Impact of $\mathrm{NHC} \pi$-acidity on $\mathrm{PCy}_{3}$ lability. (a) $\sigma$-Bonding interactions; (b) $\pi$-bonding interactions. Perspective down the $\mathrm{Ru}=$ CHR bond. 
Several consequences can be envisaged, which have a profound impact on catalytic behaviour. Most obviously, stronger $\mathrm{Ru}-\mathrm{P}$ backbonding would account for the reduced lability of the $\mathrm{PCy}_{3}$ ligand in the IMes complexes, relative to their $\mathrm{H}_{2}$ IMes analogues. Slower loss of $\mathrm{PCy}_{3}$ would in turn account for the 7-8-fold longer lifetime shown above for $\boldsymbol{u}$-GIIm, relative to $s$-GIIm. Because phosphine dissociation is required for entry into the active catalytic cycle, however, the advantage of longer lifetime is offset by slower initiation for the precatalyst $\boldsymbol{u}$-GII, and slower re-entry for the resting-state species $\boldsymbol{u}$-GIIm. This proposal clarifies the greatly enhanced initiation efficiency of phosphine-free, Hoveyda-class metathesis catalysts, ${ }^{43}$ in which the $\pi$-accepting $\mathrm{PCy}_{3}$ ligand is replaced by a $\pi$-donating ether ligand, as well as the high latency of the Cazin catalysts, in which a much more strongly $\pi$-acidic phosphite ligand is present. $^{44}$

In the Neidig study cited in the Introduction, ${ }^{9}$ the $\mathrm{NHC}$ ligands were shown to significantly reduce the binding strength of a chloride ligand in tetrahedral Fe-NHC complexes. The strengthening of the trans- $\mathrm{PCy}_{3}$ bond observed herein is a striking further manifestation of the impact of NHC donicity on $\mathrm{M}-\mathrm{L}$ binding. Beyond the specific context of olefin metathesis, similar inhibition of uptake into catalysis may be expected whenever a $\pi$-acceptor ligand must be released in order to bind substrate, particularly where this ligand is trans to an NHC. Such effects are enhanced for systems in which the strong $\sigma$ donor character of the NHC ligand is undiminished by NHC $\pi$ acceptor capacity, as illustrated here for the IMes system.

\section{Conclusions}

Strong NHC donation is arguably the defining feature of the second-generation Grubbs catalysts, as the parameter that enables their high inherent reactivity. The foregoing reveals that such strong donation wears a Janus face. Enhancing the electron density at the metal center activates the Ru-olefin intermediate, and stabilizes the Ru(Iv) metallacyclobutane intermediate. However, it also greatly amplifies $\mathrm{Ru} \rightarrow \mathrm{PCy}_{3}$ backbonding: $\mathrm{Ru}-\mathrm{P}$ bond strengths are thereby increased, and loss of phosphine is severely inhibited. This inverse trans effect is manifested in retarded initiation of the benzylidene precatalysts GII, and very slow re-entry into the catalytic cycle from the resting-state methylidene complexes GIIm.

Notwithstanding the central importance of the Grubbs catalysts and their descendents in olefin metathesis, the implications are considerably broader. The transformative impact of NHC ligands on homogeneous catalysis has long been assigned to their capacity to enhance the electron density at the metal. The influence of NHC donicity on the ancillary ligands, however, is now beginning to be examined more closely. The findings above contribute to emerging understanding of the profound impact of NHC donicity on M-L binding, and hence on catalytic behaviour. Specifically, inhibited initiation is predicted to be a general feature for M-NHC catalysts in which a $\pi$ acidic ancillary ligand occupies a latent substrate binding site, particularly where such ligands are trans to the NHC. The potential for activation of a $\pi$-accepting substrate located in this site is an obvious corollory. These findings complement recent work highlighting the labilizing effect of the NHC ligand on $\pi$ donor ligands in tetrahedral iron complexes. Differences in NHC $\pi$-acceptor capacity can thus either mitigate or reinforce trans-type $\mathrm{M}$-L bonding interactions, with major consequences for catalyst conscription and activity.

\section{Experimental}

\section{General procedures}

Reactions were carried out under $\mathrm{N}_{2}$ using standard glovebox techniques, at ambient temperature (RT; $25-27{ }^{\circ} \mathrm{C}$, unless otherwise noted). Dry, oxygen-free toluene was obtained using a Glass Contour solvent purification system. All NMR solvents (Cambridge Isotopes) were stored under $\mathrm{N}_{2}$ over Linde $4 \AA$ molecular sieves for at least $6 \mathrm{~h}$ prior to use. Dimethyl terephthalate (DMT, >99\%), 1,3,5-trimethoxybenzene (TMB, >99\%), used as internal integration standards to support quantification in ${ }^{1} \mathrm{H}$ NMR experiments, were obtained from Sigma-Aldrich. The methylidene complexes $\boldsymbol{u}$-GIIm and $\boldsymbol{s}$-GIIm were prepared by literature methods. ${ }^{\mathbf{1 7 , 4 5}} \mathrm{X}$-ray quality crystals of $\boldsymbol{u}$-GIIm were grown from toluene at $-35{ }^{\circ} \mathrm{C}$ over $48 \mathrm{~h}$.

NMR spectra were recorded on Bruker Avance 300 and 500 spectrometers at $23^{\circ} \mathrm{C}$ (unless otherwise noted), and referenced to the residual proton of the solvent. Signals are reported in ppm, relative to TMS $\left({ }^{1} \mathrm{H}\right)$ or $85 \% \mathrm{H}_{3} \mathrm{PO}_{4}\left({ }^{31} \mathrm{P}\right)$ at $0 \mathrm{ppm}$.

\section{Representative procedure for measuring decomposition rates}

In the glovebox, a J. Young NMR tube was charged with GIIm (10 $\mathrm{mg}, 0.013 \mathrm{mmol})$, TMB (ca. $0.5 \mathrm{mg})$, and $\mathrm{C}_{6} \mathrm{D}_{6}(660 \mu \mathrm{L})$. The sample was removed from the glovebox and a ${ }^{1} \mathrm{H}$ NMR spectrum was measured to establish the initial ratio of $s$-GIIm to TMB. The NMR tube was then transferred to a $40{ }^{\circ} \mathrm{C}$ oil bath (thermocouple-equipped; $\pm 1.5{ }^{\circ} \mathrm{C}$ ). The rate was determined by collecting ${ }^{1} \mathrm{H}$ NMR spectra at regular intervals. Rate profiles for $\boldsymbol{u}$-GIIm and $\boldsymbol{s}$-GIIm at $40{ }^{\circ} \mathrm{C}$ and $80^{\circ} \mathrm{C}$ are given in the ESI. $\dagger$ To examine the $\left[\mathrm{PCy}_{3}\right]$-dependence of decomposition, a corresponding experiment was carried out with $\boldsymbol{s}$-GIIm $(9.2 \mathrm{mg}$, $0.0127 \mathrm{mmol}$ ), ТMB (ca. $0.5 \mathrm{mg}$ ), and $\mathrm{PCy}_{3}$ (35.7 mg, 0.127 mmol, 10 equiv.) in $\mathrm{C}_{6} \mathrm{D}_{6}(635 \mu \mathrm{L})$ at $60{ }^{\circ} \mathrm{C}$. Time-points were taken at regular intervals until decomposition was complete.

\section{Exploring the impact of solvent on decomposition of GIIm}

These experiments were carried out as above at a bath temperature of $60{ }^{\circ} \mathrm{C}$, with NMR analysis at a single time-point $(6 \mathrm{~h})$. Thermolysis experiments in $\mathrm{CD}_{2} \mathrm{Cl}_{2}$ (b.p. $40{ }^{\circ} \mathrm{C}$ ) were carried out in thick-walled J. Young NMR tubes.

\section{Acknowledgements}

Instructive comments on the kinetics analysis by Prof. Bob Bergman (Berkeley) are acknowledged with thanks. Magdalen College, Oxford, is thanked for a Visiting Fellowship to DEF. This work was funded by NSERC of Canada. 


\section{Notes and references}

1 M. N. Hopkinson, C. Richter, M. Schedler and F. Glorius, Nature, 2014, 510, 485-496.

2 N-Heterocyclic Carbenes: Effective Tools for Organometallic Synthesis, ed. S. P. Nolan, Wiley, Weinheim, 2014.

3 N-Heterocyclic Carbenes: From Laboratory Curiosities to Efficient Synthetic Tools, ed. S. Diez Gonzalez, Royal Society of Chemistry, Cambridge, 2011.

$4 \mathrm{~N}$-Heterocyclic Carbenes in Transition Metal Catalysis and Organocatalysis, ed. C. S. J. Cazin, Springer, New York, 2011.

5 A. J. Arduengo, Acc. Chem. Res., 1999, 32, 913-921.

6 D. Bourissou, O. Guerret, F. P. Gabbai and G. Bertrand, Chem. Rev., 2000, 100, 39-91.

7 W. A. Herrmann, Angew. Chem., Int. Ed., 2002, 41, 12901309.

8 C. M. Crudden and D. P. Allen, Coord. Chem. Rev., 2004, 248, 2247-2273.

9 K. L. Fillman, J. A. Przyojski, M. H. Al-Afyouni, Z. J. Tonzetich and M. L. Neidig, Chem. Sci., 2015, 6, 1178-1188.

10 D. Marchione, L. Belpassi, G. Bistoni, A. Macchioni, F. Tarantelli and D. Zuccaccia, Organometallics, 2014, 33, 4200-4208.

11 A. Comas-Vives and J. N. Harvey, Eur. J. Inorg. Chem., 2011, 5025-5035.

12 M. Scholl, T. M. Trnka, J. P. Morgan and R. H. Grubbs, Tetrahedron Lett., 1999, 40, 2247-2250.

13 J. Huang, E. D. Stevens, S. P. Nolan and J. L. Petersen, J. Am. Chem. Soc., 1999, 121, 2674-2678.

14 M. S. Sanford, J. A. Love and R. H. Grubbs, J. Am. Chem. Soc., 2001, 123, 6543-6554.

15 H.-C. Yang, Y.-C. Huang, Y.-K. Lan, T.-Y. Luh, Y. Zhao and D. G. Truhlar, Organometallics, 2011, 30, 4196-4200.

16 K. Getty, M. U. Delgado-Jaime and P. Kennepohl, J. Am. Chem. Soc., 2007, 129, 15774-15776.

17 J. A. M. Lummiss, N. J. Beach, J. C. Smith and D. E. Fogg, Catal. Sci. Technol., 2012, 2, 1630-1632.

18 The change in the NHC ligand present in $\boldsymbol{s}$-GIIm and $\boldsymbol{u}$-GIIm results in limited steric perturbation, as indicated by the comparable \% buried volume for the IMes and H2IMes ligands (26\% vs. 27\%, respectively). See: ref. 19.

19 S. Diez-Gonzalez and S. P. Nolan, Coord. Chem. Rev., 2007, 251, 874-883.

20 H. Jacobsen, A. Correa, A. Poater, C. Costabile and L. Cavallo, Coord. Chem. Rev., 2009, 253, 687-703.

21 N. S. Antonova, J. J. Carbo and J. M. Poblet, Organometallics, 2009, 28, 4283-4287. As DFT calculations were carried out on a model $\mathrm{RuCl}_{2}(\mathrm{NHC})\left(\mathrm{PH}_{3}\right)\left(=\mathrm{CH}_{2}\right)$ system, the computed $\mathrm{Ru}-\mathrm{NHC}$ back-donation should be regarded as a lower limit.

22 Y. Minenkov, G. Occhipinti, W. Heyndrickx and V. R. Jensen, Eur. J. Inorg. Chem., 2012, 1507-1516.

23 O. Back, M. Henry-Ellinger, C. D. Martin, D. Martin and G. Bertrand, Angew. Chem., Int. Ed., 2013, 52, 2939-2943.

24 A. Liske, K. Verlinden, H. Buhl, K. Schaper and C. Ganter, Organometallics, 2013, 32, 5269-5272.
25 G. Ciancaleoni, N. Scafuri, G. Bistoni, A. Macchioni, F. Tarantelli, D. Zuccaccia and L. Belpassi, Inorg. Chem., 2014, 53, 9907-9916.

26 S. V. C. Vummaleti, D. J. Nelson, A. Poater, A. Gomez-Suarez, D. B. Cordes, A. M. Z. Slawin, S. P. Nolan and L. Cavallo, Chem. Sci., 2015, 8, 1895-1904.

27 For early computational or integrated experimental/ computational studies showing evidence of backbonding onto NHC ligands, see: (a) M. Tafipolsky, W. Scherer, K. Öfele, G. Artus, B. Pedersen, W. A. Herrmann and G. S. McGrady, J. Am. Chem. Soc., 2002, 124, 5865-5880; (b) D. Nemcsok, K. Wichmann and G. Frenking, Organometallics, 2004, 23, 3640-3646; (c) X. Hu, I. CastroRodriguez, K. Olsen and K. Meyer, Organometallics, 2004, 23, 755-764; (d) G. Occhipinti, H.-R. Bjorsvik and V. R. Jensen, J. Am. Chem. Soc., 2006, 128, 6952-6964; (e) H. Jacobsen, A. Correa, C. Costabile and L. Cavallo, J. Organomet. Chem., 2006, 691, 4350-4358; ( $f$ ) E. F. Penka, C. W. Schlapfer, M. Atanasov, M. Albrecht and C. Daul, J. Organomet. Chem., 2007, 692, 5709-5716.

28 For early experimental evidence of the $\pi$-acceptor ability of NHC ligands, see: (a) A. A. D. Tulloch, A. A. Danopoulos, S. Kleinhenz, M. E. Light, M. B. Hursthouse and G. Eastham, Organometallics, 2001, 20, 2027-2031; (b) L. Mercs, G. Labat, A. Neels, A. Ehlers and M. Albrecht, Organometallics, 2006, 25, 5648-5656; (c) M. D. Sanderson, J. W. Kamplain and C. W. Bielawski, J. Am. Chem. Soc., 2006, 128, 16514-16515; (d) S. Fantasia, J. L. Petersen, H. Jacobsen, L. Cavallo and S. P. Nolan, Organometallics, 2007, 26, 5880-5889; (e) D. M. Khramov, V. M. Lynch and C. W. Bielawski, Organometallics, 2007, 26, 6042-6049.

29 M. Alcarazo, T. Stork, A. Anoop, W. Thiel and A. Fürstner, Angew. Chem., Int. Ed., 2010, 49, 2542-2546.

30 S. H. Hong, A. G. Wenzel, T. T. Salguero, M. W. Day and R. H. Grubbs, J. Am. Chem. Soc., 2007, 129, 7961-7968.

31 J. A. M. Lummiss, B. J. Ireland, J. M. Sommers and D. E. Fogg, ChemCatChem, 2014, 6, 459-463.

32 J. A. M. Lummiss, W. L. McClennan, R. McDonald and D. E. Fogg, Organometallics, 2014, 33, 6738-6741.

33 For derivation of the rate laws for the dissociative and associative pathways, see the ESI. $\dagger$ For a succinct derivation of the rate law for the dissociative pathway, see ref. 30 .

34 Y. Minenkov, G. Occhipinti and V. R. Jensen, Organometallics, 2013, 32, 2099-2111.

35 B. J. van Lierop, J. A. M. Lummiss and D. E. Fogg, in Olefin Metathesis-Theory and Practice, ed. K. Grela, Wiley, Hoboken, NJ, 2014, ch. 3, pp. 85-152.

36 T. M. Trnka, M. W. Day and R. H. Grubbs, Angew. Chem., Int. Ed., 2001, 40, 3441-3444.

37 A. W. Addison, T. N. Rao, J. Reedijk, J. van Rijn and G. C. Verschoor, J. Chem. Soc., Dalton Trans., 1984, 13491356.

38 G. Frenking, K. Wichmann, N. Froehlich, J. Grobe, W. Golla, D. L. Van, B. Krebs and M. Laege, Organometallics, 2002, 21, 2921-2930.

39 B. F. Straub, Angew. Chem., Int. Ed., 2005, 44, 5974-5978. 
40 See: ref. 22, 34 and background discussion in: Y. Zhao and D. G. Truhlar, Org. Lett., 2007, 9, 1967-1970.

41 T. Leyssens, D. Peeters, A. G. Orpen and J. N. Harvey, New J. Chem., 2005, 29, 1424-1430.

42 N. Fey, A. G. Orpen and J. N. Harvey, Coord. Chem. Rev., 2009, 253, 704-722.
43 J. M. Bates, J. A. M. Lummiss, G. A. Bailey and D. E. Fogg, ACS Catal., 2014, 4, 2387-2394.

44 T. E. Schmid, X. Bantreil, C. A. Citadelle, A. M. Z. Slawin and C. S. J. Cazin, Chem. Commun., 2011, 47, 7060-7062.

45 For further improvements in synthesis of GIIm, see: J. A. M. Lummiss, A. G. G. Botti and D. E. Fogg, Catal. Sci. Technol., 2014, 4, 4210-4218. 